San Jose State University

SJSU ScholarWorks

$5-1-2004$

\title{
The Effect of Body Position and Mattress Type on Interface Pressure in Quadriplegic Adults-a Pilot Study
}

Parivash Moody

San Jose State University

Follow this and additional works at: https://scholarworks.sjsu.edu/etd_projects

Part of the Other Nursing Commons

\section{Recommended Citation}

Moody, Parivash, "The Effect of Body Position and Mattress Type on Interface Pressure in Quadriplegic Adults-a Pilot Study" (2004). Master's Projects. 794.

DOI: https://doi.org/10.31979/etd.shm8-xqcy

https://scholarworks.sjsu.edu/etd_projects/794

This Master's Project is brought to you for free and open access by the Master's Theses and Graduate Research at SJSU ScholarWorks. It has been accepted for inclusion in Master's Projects by an authorized administrator of SJSU ScholarWorks. For more information, please contact scholarworks@sjsu.edu. 

SCHOOL 1

MASTER'S PROGRAM P

PROJECT SIC

STUDENT NAME: Parivash Moody RN

SEMESTER ENROLLED: Spring 2004
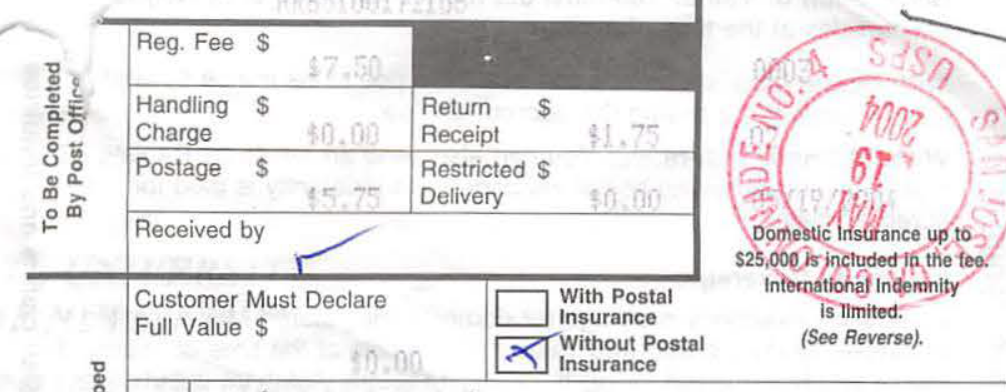

International Indemity

is limited.

(See Reverse).

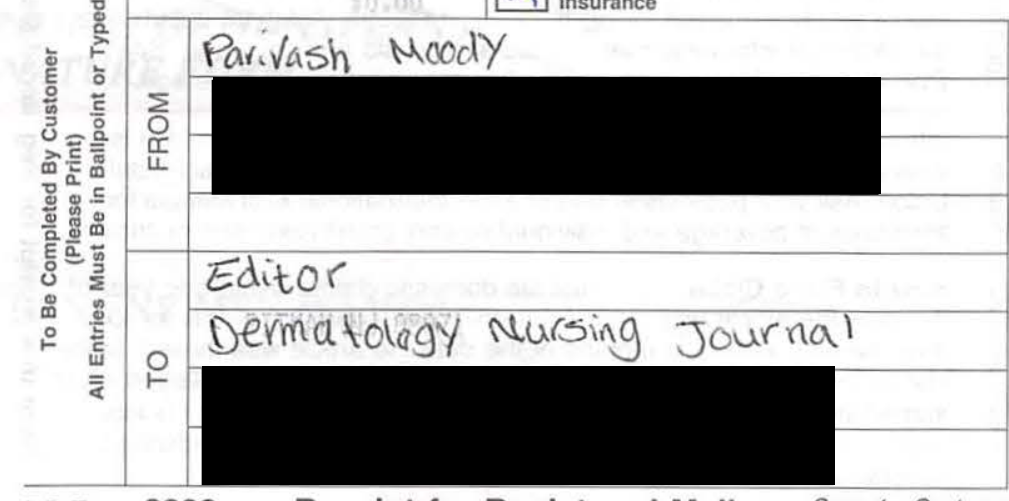

PS Form 3806, Receipt for Registered Mail Copy 1 -Customer June 2002

(See Information on Reverse)

TITLE OF PROJECT:

For delivery information, visit our website at www.usps.com ${ }^{\circledR}$

\section{"The Effect of Body Position and Mattress Type on Interface \\ Pressure in Quadriplegic Adults-a Pilot Study”}

\section{NAME OF JOURNAL: The Journal of Dermatology}

The project and the manuscript have been successfully completed and meet the standards of the School of Nursing and University. The project demonstrates the application of professional knowledge, clinical expertise, and scholarly thinking. An abstract of the project and two copies of the manuscript are attached.

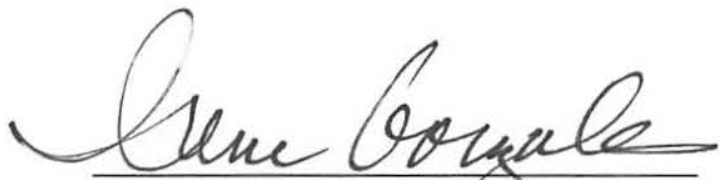

ADVISOR'S SIGNATURE

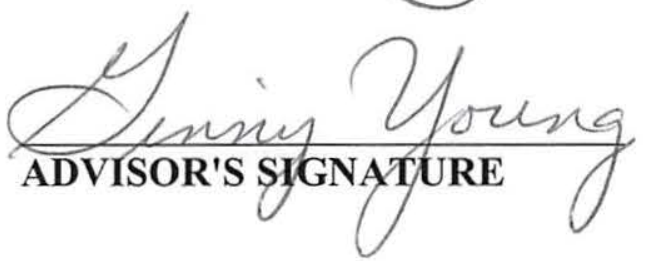

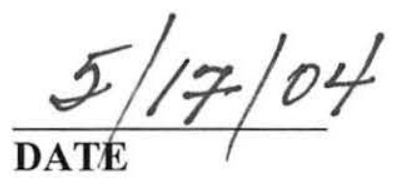

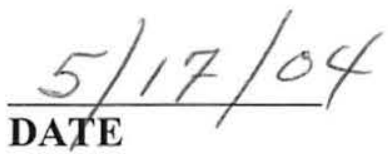

Please submit the form to the Graduate Coordinator. Attach abstract, two copies of the manuscript, and the documentation of submission to the journal (i.e., postal receipt) 
The Effect of Body Position and Mattress Type on Interface Pressure in Quadriplegic Adults-a Pilot Study

Parivash Moody R.N., B.S.N., M.S.N./F.N.P. Candidate, Irene Gonzales Ph.D., R.N., C.N.P., Virigina Young Cureton, Dr. P.H., R.N.

San Jose State University School of Nursing, San Jose, California

\begin{abstract}
A convenience sample of 20 adults with quadriplegia was studied to determine preferred position and mattress to minimize occurrence of pressure ulcers. Lower positions produced lower interface pressures. Pressure relieving mattress reduced interface pressures more than a pressure reducing mattress.
\end{abstract}


Introduction

Pressure ulcers are a major health care problem in terms of client mobility, suffering, and the associated economic impact. Approximately one million people in the United States are affected by pressure ulcers (Young, Evans \& Davis 2003), costing close to $\$ 1.6$ billion annually. The estimated cost, per hospital stay, ranges from $\$ 2,000$ to $\$ 30,000$ for stage 1,2 , or 3 pressure ulcer. The cost of managing a stage 4 ulcer was estimated to be as high as $\$ 70,000$. The incidence of pressure ulcer formation ranges from $12 \%$ to $66 \%$ in surgical clients; $17 \%$ to $27 \%$ in cardiac surgical clients; and $20 \%$ to $32 \%$ in hospitalized elderly patients (Schouchoff, 2002).

Individuals with impaired circulation due to their immobility are at greater risk of developing pressure sores. This group undergoes delayed healing and, therefore, prolonged suffering and continued expense.

The incidence of pressure sores among the neurologically impaired clients at the University of Florida Health Science Center (Revis, 2000), occurs at a rate of $5 \%-8 \%$ and the life-time risk is estimated to be $25 \%$ $85 \%$. Mortality from pressure sores is listed as the direct cause of death in $7 \%-8 \%$ of all paraplegics.

Because pressure ulcers clearly have a significant impact on a client's health, quality of life, and cost of care; prevention, rather than a 
cure, must remain the focus (Clay, 2000). Pressure ulcers can be prevented, and the cost of prevention was less costly than the treatment (Hopkins, B., Hanlon, M., Syke, S., Rose, T., \& Cleary, A., 2000). The primary goal of pressure sore prevention is the removal or reduction of pressure to the skin, thus allowing increased blood flow to the area. The principle behind any of the pressure-relieving approaches is to diffuse the pressure load at the site where the body has contact with the supporting surface. Coats (2002) defined support surfaces as devices that decrease or eliminate interface pressure.

These devices are divided into pressure reduction surfaces (such as a Urethane mattress), and pressure relief surfaces (such as the Dynamic air mattress). An extensive review regarding the effectiveness of support surfaces for prevention and treatment of pressure sores was conducted by Bergstrom (2000). Bergstrom further identified the superiority of higher technology surfaces for the prevention of pressure sores, and the necessity for more research to be performed with these devices. Despite these data, no studies have been conducted on the effect of interface pressures in the quadriplegic population.

Interface pressure is the pressure applied to the skin and underlying tissue by the supporting surface (Defloor, 2000). Studies have been conducted relating to the reduction of interface pressure on healthy 
volunteers. Participants were either healthy volunteers or newly admitted patients in the intensive care unit or operating room. The health condition of an individual with quadriplegia is significantly different from a healthy person. According to Maklebust and Sieggreen (1996), good tone in the gluteal musculature of a healthy person tends to elevate the sacrum from the support surface on which the person was reclining. This good tone reduces pressure in a healthy subject. A higher interface pressure in individuals with compromised health has been documented.

Literature Review

Pressure sores develop as a result of a two step process. First, there is an occlusion of blood vessels by external pressure. Second, there is endothelial damage of arterioles and micro-circulation due to friction and shearing forces (Hawkins \& Stone, 1999). Pressure damage occurs when the skin and other tissues are directly compressed between the bone and another hard surface (Clay, 2000). One of the common reasons for malnutrition or death of tissue is the blockage of blood flow to the arterioles (Guyton \& Hall, 2000). This blockage is often caused by prolonged external pressure.

There is an inverse relationship between time and pressure. $A$ person can endure a great amount of pressure during a short period of time or a low amount of pressure during a longer period of time without the 
tissue sustaining damage. Pressure multiplied by the duration of time will create pressure ulcers. Pressure ulcers form when pressure exceeds the tissue capillary pressure of 25 to $32 \mathrm{~mm} \mathrm{Hg}$ (Armstrong and Bartz, 2001).

Clients with neurological impairments or clients already suffering from respiratory problems are at a higher risk of developing pulmonary complications (Hawkins \& Stone,1999). A frequent change of body position helps to prevent respiratory complications.

Although national guidelines support frequent repositioning to prevent complications, many issues remain unresolved. Some of the issues identified were health care provider shortage, a lack of time, lack of staff member commitment, and consistency with regard to the repositioning of a client every 2 hours (Clark,1998). A turning regimen must be maintained 24 hours a day. The client's need for uninterrupted sleep must be considered along with the 24 hour per day turning regimen. Further research studies can provide resolution for this apparent conflict.

Five different operating room table mattresses were assessed related to interface pressure. The results indicated that interface pressure was unusually high on any operating room table. Results also pointed to the time period of immobilization, during surgery, as a significant factor contributing to the formation of pressure sores (Schuijmer, 2000). 
Despite the use of the Poly-Urethane reducing pressure mattress, none of the mattresses significantly reduced the interface pressure.

In 1999 interface pressures were measured on four different cushions using healthy volunteers. The Repose air cushion was the thickest and the most effective for reducing pressure. This cushion was composed of air-filled sacks. The inflation of the sacks was adjustable according to the client's needs. Although the Repose air cushion had been developed and used to prevent pressure sores, a study of the effectiveness of this cushion on clients with quadroplegia had not been conducted (Defloor, 1999)

Defloor (2000) examined the effect of body position and mattress on interface pressure on a group of healthy volunteers. The study utilized two kinds of mattresses, a standard mattress and a pressure reducing mattress. The results indicated that the prone position (lying flat on the abdomen) generated a lower interface pressure compared to the supine (lying flat on the back) zero degree position. A standard hospital mattress had consistent interface pressures of $\geq 100 \mathrm{~mm} \mathrm{Hg}$. This elevated interface pressure will block circulation in a healthy individual, unless repositioning is provided every 1 or 2 hours. 


\section{Research Questions}

The purpose of this study was to examine the range of pressure on the body of an individual with quadriplegia utilizing two types of mattresses and in four different positions. The research focused on 2 questions:

1. Which position for a client with quadriplegia was associated with the lowest interface pressure?

2. Taking into account different body positions, does one mattress type have a higher pressure-reducing effect than another mattress type?

\section{Methodology}

This quantitative, cross-sectional study measured interface pressures using 4 body positions and 2 mattress types to determine the best position and the best mattress to reduce the prevalence and/or severity of pressure sores. IRB approval and consent was obtained prior to data collection.

Positions

The interface pressure was measured in four different positions on a "Polyethylene-Urethane" pressure reducing mattress and on a "Dynamic Flotation" mattress. 
This study measured interface pressure while the participant was in four different positions. These four selected positions are the most common positions for an individual with quadriplegia who is in bed:

1. Three supine positions, with the head of the bed elevated at $45^{\circ}$, $60^{\circ}, 65^{\circ}$.

2. One lateral (lying on one side) position, with the head of the bed elevated at $30^{\circ}$.

In the three supine positions, only the elevation of the head of the bed was varied. A pillow was placed under the knees for support in all positions. In the $30^{\circ}$ lateral position, the participant was turned to his/her right side. A pillow was placed between the legs.

Persons with quadriplegia are immobile and may have a tracheotomy; they may be unable to move their head and clear their airway; therefore the prone and supine flat position would be contraindicated due to risk of airway obstruction. In addition, interface pressures in the $90^{\circ}$ position (High-Fowler's) were not measured due to quadriplegic individual's immobility and inability to maintain this position in bed.

Interface Measurement Tool

The X-Sensor Pressure Mapping System was used to measure the different interface pressures. Interface pressure is the pressure applied to 
the skin and underlying tissue by the surface that is supporting it. This clinical tool measures interface pressure distribution between the human body and contact surfaces, such as a bed. Thirty-two millimeters of mercury $(\mathrm{mm} \mathrm{Hg})$ interface pressure is the critical value for developing a pressure ulcer. Keeping the interface pressure below $32 \mathrm{~mm} \mathrm{Hg}$ is one of the goals for prevention of pressure sores.

The X-Sensor consists of a soft and flexible pad that has 6,912 sensors. Each sensor is filled with air. Pressure on a sensor causes the air to shift in the air tube. A transducer converts this air shift into a digital signal. The signal of each separate sensor is registered and computerized. The Pressure Mapping System allows measurement of pressure on each sensor and also measures the interface pressure. After placing an individual on the top of the pad, the system provides an image of pressure over the sensing area. Reliability and validity testing was conducted and calibration standards were documented (Hastings, M.K., Commean, P.K., Smith, K.E., Pilgram, T.K., \& Mueller, M.J., 2003;

Stinson, M.D., Porter-Armstrong, A.P., \& Eakin, P., 2003b).

Mattresses

Two types of therapeutic mattresses were selected. One was a pressure relieving mattress (Dynamic Flotation mattress) and the other was a pressure reducing mattress (Polyethylene-Urethane mattress). 
The Urethane mattress is constructed with a top layer of polyethylene-urethane in the form of visco-elastic foam and a lower layer of resilient polyether. The mattress is covered by an impermeable, shrink resistant stretch fabric, made of $80 \%$ cotton and $20 \%$ polyester.

The Dynamic Flotation mattress (DFS 3) consists of air-filled sacks that stimulate blood circulation, improve tissue nutrition, and increase oxygenation. Support is provided by cells that are grouped in four sections, each of which has a specific function. The "head cells" under the head remain at a constant pressure for pillow stability. The "torso area" is served by special cells that fully support both lying and sitting positions. The "thigh to the foot area" of the mattress has cells that maximize pressure relief. The "heel area" of the mattress has special cells that maximize the pressure relief under the heels.

Procedure

Interface pressure was measured on a Polyethylene - Urethane mattress and on a Dynamic Flotation (DFS 3) mattress for each of the participants in the four selected positions. A mechanical lift was used for transferring the participants. After a calibration of the pressure sensors (less than 2 seconds), the participant was placed on the first mattress in the first position. After approximately 1 minute $30 \mathrm{sec}$, the computer recorded a digital readout of the interface pressure. 
The same procedure was used for each of the other positions. Prior to every measurement, the sensor pad was recalibrated. Results were stored and tabulated after each measurement.

Results

\section{Demographics}

A convenience sample of 12 male and 8 female adults with quadriplegia was studied. The participants were residents of a local state facility. Their age ranged from 20 years to 54 years $(M=40.5, S D=$ 8.50). The participants' $B M I$ range was 15.0 to $28.2 ;(M=22.18, S D=$ 3.95). Normal BMI range is 18.5 to 24.9 (CDC1996).

Once the sample participants were selected and data was collected on both mattresses, a single sample $t$ - test $(p<0.01)$ was used to compare the mean of the interface pressures for each position against 32 $\mathrm{mm} \mathrm{Hg}$ (the clinical standard of ideal interface pressure; $\leq 32 \mathrm{~mm} \mathrm{Hg}$ is considered normal).

Position.

The lower the degree of position (other than zero), the lower the interface pressure on both mattresses (Figure 1). The interface pressure in the 65 degree supine position was higher than any other position, on both mattresses (Table 1). The interface pressure in the $\mathbf{3 0}$ degree lateral position was lower than any other position, on both mattresses (Table 2). 


\section{Mattress.}

The mean of the interface pressures for the Dynamic Flotation mattress was $13 \%$ lower than that of the Polyethylene - Urethane mattress. The lowest interface pressure was measured during the $30^{\circ}$ lateral position on both mattresses. The highest interface pressure was measured while in the $65^{\circ}$ supine position on both mattresses (Table 1 and Table 2).

\section{Discussion and Implications for Nursing}

The results of this study indicated that the $30^{\circ}$ lateral position caused less pressure compared with the other three positions on both the Dynamic Flotation mattress and the Polyethylene - Urethane mattress. The higher degree body positions $\left(60^{\circ}\right.$ and $65^{\circ}$ head elevation) rendered higher interface pressures; therefore the $60^{\circ}$ and $65^{\circ}$ positions should be avoided, as much as possible. If the patients are required to be positioned in a position higher than $45^{\circ}$, their health care providers should monitor them closely.

The selection decision regarding type of pressure reducing mattress should be based on a holistic assessment of the patient's health condition and living environment. 
Interface pressures with the Polyethylene - Urethane mattress were an average of $13 \%$ higher than the Dynamic Flotation mattress, for all four positions.

There are some challenges in the use and maintenance of the Dynamic Flotation mattress. Interface pressure is only one factor to be considered when selecting mattress type. Noise produced by the air mattress pump, the potential for mechanical breakdown, the high rental cost, or the high purchase cost are other factors that should be considered before selecting a mattress. All dynamic air mattresses should be assessed at regular intervals by a care provider to insure that the electrical power is on and that the mattress is functioning properly. If there is an interruption in the electrical power, the mattress will deflate, and the patient will be lying on a metal surface. Dynamic air mattresses can be safely used in the home, if there is a backup electric generator.

All bedridden patients should be considered at risk of pressure ulcer development. A nursing care plan should be formulated and implemented based on the patient's medical condition, type, and duration of immobilization, safety, comfort, and living environment. 


\section{Limitations}

A small convenience sample was used in this study. Despite the sample size, the participants were from a population that has a high rate of morbidity and mortality from pressure sores.

The sample was homogeneous and the participants were all individuals with quadriplegia. Consistency in data collection procedures such as measurements of interface pressure by the same staff members, using the same equipment utilizing the same procedures, and at the same time of day maximized the degree of control. Further research with a larger sample that is randomly selected and randomly assigned will allow for greater generalizability. The majority of participants had basal metabolic indices (BMI) that were within normal range $(M=22.18, S D=$ 3.95). Further research with overweight and underweight individuals may provide different results. This study was done in only one institution. A multi-center randomized clinical trial would increase clinical impact across settings 


\section{References}

Armstrong, D., \& Bartz, P. (2001). An integrative review of pressure relief in surgical patients. The Association of Preoperative Registered Nurses, 73, 3. Retrieved October 16, 2003, from Shttp://libaccess.sjsu.edu:2059/ovidweb.cgi

Bergstrom, N. (2000). Specially designed products to prevent the heel pressure sores are more effective than standard mattresses. Evidenced Based Nursing, 3(2), 54.

CDC, Body Mass Index (BMI), (1996). Retrieved October 16, 2003, from Shttp://198.246.96.2/nccdphp/dnpa/bmi/bmi-adult-formula.htm

Clark, M. (1998). Repositioning to prevent pressure sores. Nursing Standard 13, $58-64$.

Clay, M. (2000). Pressure sore prevention in nursing homes. Nursing standard, 14, 2-10.

Coats, B. (2002). Use of support surfaces in the ICU. Critical Care Nursing Quarterly, 25 (1), 22 - 32.

Guyton, A. C., \& Hall, J. E. (2000). Functional organization of the human body. Guyton \& E. Hall (Eds.). Medical physiology (p. 7).

Philadelphia: W. B. Saunders.

Defloor, T. (1999). Sitting posture and prevention of pressure ulcers. Applied Nursing Research, 12, 136-142. 
Defloor, T. (2000). The effect of position and mattress on interface pressure. Applied Nursing Research, 13 (1), 2-10.

Hastings, M.K., Commean, P.K., Smith, K.E., Pilgram, T.K., \& Mueller, M.J. (2003). Aligning anatomical structure from spiral X-ray computed tomography with plantar pressure data. Clinical Biomechanics (Bristol, Avon). 18(9), 877-82.

Hawkins, S., \& Stone, K. (1999). An holistic approach to turning patients. Nursing Standard, 14 (3), 3.

Hopkins, B., Hanlon, M., Syke, S., Rose, T., \& Cleary, A. (2000). Reducing nosocomial pressure ulcers in an acute care facility. Journal of Nursing Care Quality 14 (3), 28.

Maklebust, J., \& Sieggreen, M. (1996). Pressure ulcers guidelines for prevention and nursing management. (p.32). West Dundee, IL: N-S Publications.

Revis, D. (2000). Pressure ulcers, non-surgical treatment. Medicine. Retrieved April 25, 2001 from http://www.emedicine.com/plastic/topic424.htm

Schouchoff, B. (2002). Pressure ulcer development in the operating room. Critical Care Nursing Quarterly. 25, 76-82.

Schuijmer, J.(2000). Preventing pressure ulcers. Applied Nursing Research, 12, 134 - 141. 
Stinson, M.D., Porter-Armstrong, A.P., \& Eakin, P. (2003a). Measuring interface pressure: a laboratory-based investigation into the effects of repositioning and sitting. American Journal Occupational Therapy. 56(2), 185-90.

Stinson, M.D., Porter-Armstrong, A.P., \& Eakin, P. (2003b). Pressure mapping systems: reliability of pressure map interpretation. Clinical Rehabilitation. 17(5), 504-11.

Young, Z. F., Evans. A., Davis, J. (2003). Nosocomial pressure ulcer prevention. Journal of Nursing Administration. 33 (7/8), 380-383. 
Table 1

Interface pressure $(\mathrm{mm} \mathrm{Hg})$ Mean, Standard Deviation, and Single Sample $t$ Test

\begin{tabular}{llll}
\hline $\begin{array}{l}\text { Dynamic Flotation } \\
\text { Mattress }\end{array}$ & Mean & $\begin{array}{l}\text { Standard } \\
\text { Deviation }\end{array}$ & $\begin{array}{l}\text { Single Sample } \\
t \text { test }\end{array}$ \\
\hline Position: $45^{\circ}$ & 13.35 & 1.80 & $-46^{\star \star}$ \\
Position: $60^{\circ}$ & 14.57 & 1.58 & $-45^{\star *}$ \\
Position: $65^{\circ}$ & 15.38 & 1.71 & $-43^{\star *}$ \\
Position: $30^{\circ}$ Lateral & 11.81 & 1.43 & $-65^{\star *}$ \\
\hline
\end{tabular}

* *Significance $p<0.01$ 
Table 2

Interface pressure $(\mathrm{mm} \mathrm{Hg})$ Mean, Standard Deviation, and Single Sample $t$ Test

\begin{tabular}{llll}
\hline $\begin{array}{l}\text { Polyethylene-Urethane } \\
\text { Mattress }\end{array}$ & Mean & $\begin{array}{l}\text { Standard } \\
\text { Deviation }\end{array}$ & $\begin{array}{l}\text { Single Sample } \\
t \text { test }\end{array}$ \\
\hline Position: $45^{\circ}$ & 15.11 & 1.71 & $-44^{* \star}$ \\
Position: $60^{\circ}$ & 16.11 & 1.61 & $-43^{* \star}$ \\
Position: $65^{\circ}$ & 16.41 & 1.68 & $-39^{* *}$ \\
Position: $30^{\circ}$ Lateral & 13.81 & 1.45 & $-56^{* *}$ \\
\hline * *Significance $\mathrm{p}<0.01$ & & &
\end{tabular}




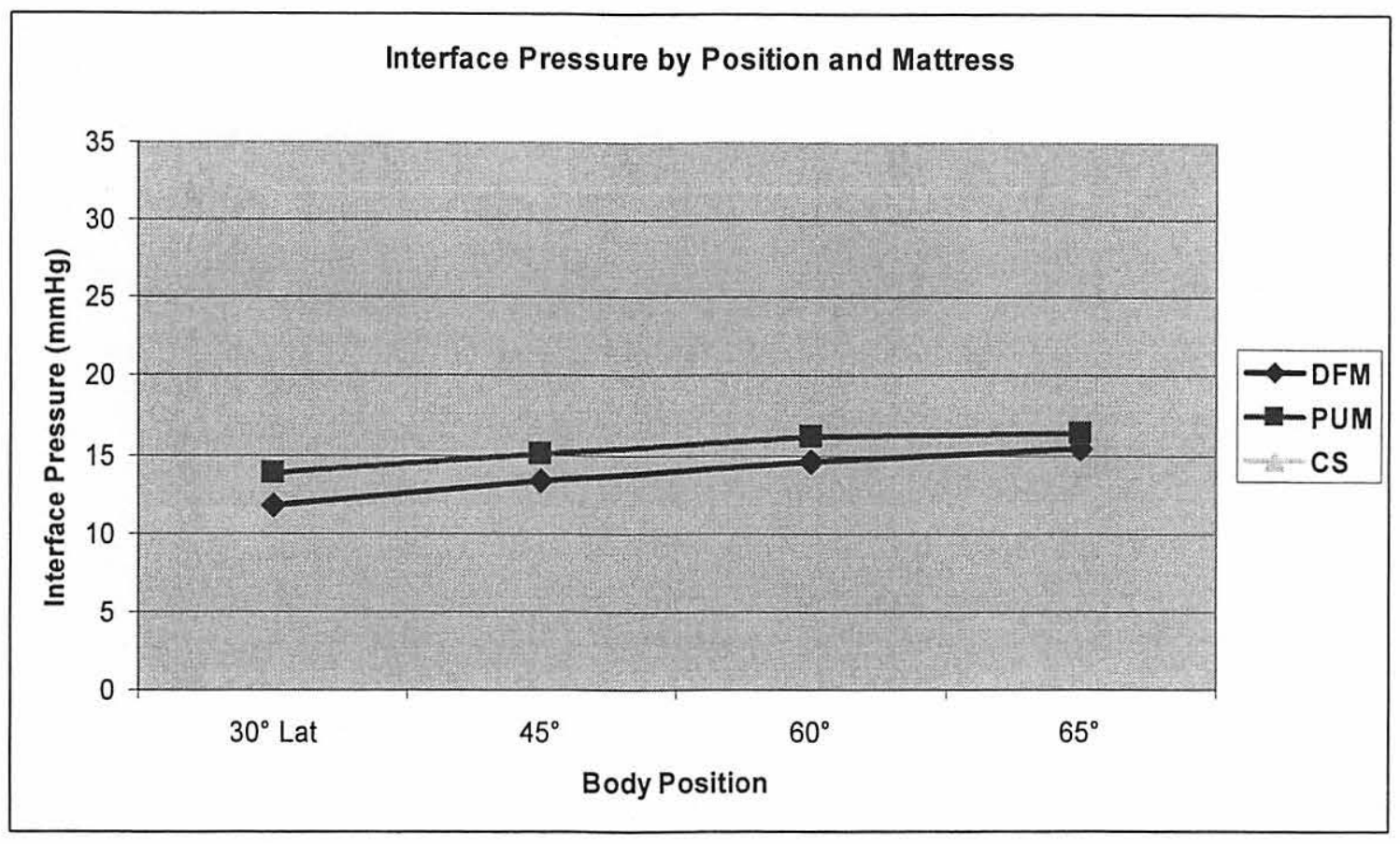

Figure 1. Comparison of interface pressures using two different mattresses: Dynamic Flotation mattress (DFM) and PolyethyleneUrethane mattress (PUM) compared to the critical standard of $32 \mathrm{~mm} \mathrm{Hg}$. Greater to or equal to the interface pressure of $32 \mathrm{~mm} \mathrm{Hg}(\mathrm{CS})$ is considered dangerous and a concern for possible body pressure damage. 